\title{
ITO-free large-area flexible organic solar cells with an embedded metal grid
}

Seungkeun Choi, Yinhua Zhou, Wojciech Haske, Jae Won Shim, Canek FuentesHernandez, and Bernard Kippelen ${ }^{\dagger}$,

Center for Organic Photonics and Electronics

School of Electrical and Computer Engineering

Georgia Institute of Technology, Atlanta, GA 30332 (U.S.A.)

\begin{abstract}
We report on ITO-free large-area flexible organic solar cells with embedded thick metal grids. Embedded thick metal grids on flexible substrates allow uniform spin coating of thin layers of PEDOT:PSS (PH1000) semitransparent electrodes and organic semiconductor layers. A transparent SU8 photo-patternable polymer is used as a flexible substrate. Electroplated copper metallic grids, up to $15 \mu \mathrm{m}$ thick, defined by photolithography, produce a shadow area of $5.5 \%$ of the active area. Inverted solar cells with an active area of $9.3 \pm 0.2 \mathrm{~cm}^{2}$, exhibited a fill factor of $0.53 \pm 0.06$, and an open-circuit voltage of $808 \pm 5 \mathrm{mV}$ and a short-circuit current density of $5.5 \pm 0.5$ $\mathrm{mA} / \mathrm{cm}^{2}$, yielding a power conversion efficiency of $2.4 \pm 0.4 \%$ under $100 \mathrm{~mW} / \mathrm{cm}^{2}$ air mass $1.5 \mathrm{G}$ illumination. The fill-factor and open circuit voltage values of largearea solar cells are comparable to values reported on small-area solar cells.
\end{abstract}

\section{Introduction}

Over the last decade, organic photovoltaics (OPV) have been extensively investigated for their potential to develop low-cost, flexible, and light-weight solar

\footnotetext{
${ }^{\dagger}$ Corresponding author: Kippelen@ece.gatech.edu
} 
cells [1-3]. The power conversion efficiency (PCE) of OPV has rapidly improved during the past few years and now exceeds $10 \%[4,5]$. These laboratory-scale OPVs are often demonstrated as individual cells, with a small active area (typically less than few $\mathrm{cm}^{2}$ ), usually fabricated on rigid, or even flexible, substrates having indium-tinoxide (ITO) transparent electrodes [1]. However, ITO is brittle and expensive, so the realization of mechanically stable large-area OPVs on flexible substrates will require developing alternative transparent electrodes that replace ITO [6, 7].

Finding suitable replacements for ITO is still an important technical challenge. Two most widely used ITO alternatives are a highly conductive poly $(3,4-$ ethylenedioxythiophene): poly(styrenesulfonate) (PEDOT:PSS) [6, 8, 9] and thin semitransparent layers of metal or carbon nanotubes [10-12]. In order to obtain sheet resistance values comparable to those of ITO (10-15 $\Omega / \mathrm{sq}$.$) , PEDOT:PSS is often$ combined with silver nanowire or thin metallic grid manufactured with various processing techniques $[10,11,13-21]$. While all these efforts aim to develop a transparent electrode that can replace ITO, the performance of large-area OPVs is still significantly limited by parasitic series resistance effects even in solar cells that use ITO transparent electrodes (which display sheet resistance values that are at least two orders of magnitude lower than those reported for PEDOT:PSS) [22-25]. This is because the power loss due to series resistance is proportional to the square of the solar cell length. Furthermore, parasitic series resistances become a limiting factor when implementing OPV modules, forcing the use of the so-called stripe geometry wherein several cells consisting of narrow stripes are connected in series. This method is widely used in OPV modules manufactured with roll-to-roll processes [3, 26-30]. A disadvantage of this method is that the area used by the stripe-to-stripe connections reduces the overall active area of the module (typically around 20\%), leading to a 
significant reduction of the power conversion efficiency in modules compared to small-area cells [31]. Hence a need exists to develop alternatives to ITO with higher conductivity and better mechanical properties for the realization of large-area OPV solar cells and modules.

We recently demonstrated the realization of bottom electrodes comprising thick metal grids and a highly conductive grade of PEDOT:PSS (Clevios PH 1000, H. C. Starck), which was used as a substitute for conventional ITO-coated substrates in large-area OPVs [22] and organic light-emitting diodes (OLEDs) [32] [22, 23, 33]. The benefits of a thicker metal grid is obvious as it provides more conductive current paths compared to a thin film based metal grid [23]. In fact, it was shown that the thicker grid was essential to minimize resistive power loss from the grid itself [33]. Furthermore, it was proven that the same metal design can be applied to much larger areas without significantly increasing resistive power loss densities by using the same grid design with a thicker grid [23]. In such devices, the organic semiconductor layers were thermally evaporated rather than spin-coated. To facilitate solution processing, a better approach would be to have metal grids embedded in the substrate [34, 35].

Herein, we report on the demonstration of ITO-free flexible large-area organic solar cells with an embedded metal grid fabricated on a SU8 substrate. Because the thick metal grid was embedded within the flexible substrate, layers of PEDOT:PSS (PH1000) and organic semiconductors were spin coated uniformly on top of a largearea substrate. An SU8 photo-patternable polymer was used as a flexible substrate as it has good optical transmittance in the visible wavelength. Copper was electroplated up to $15 \mu \mathrm{m}$ creating embedded metal grids. The shadow area loss due to the metal grids is $5.5 \%$ of the active area. The completed device had an inverted structure of SU8/embedded-metal-grid/PEDOT:PSS(PH1000)/PEIE/P3HT:ICBA/MoO $3 / \mathrm{Ag}$ with 
an active area of of $9.3 \mathrm{~cm}^{2}$. The device exhibited a fill factor of 0.6 , a short-circuit current density of $5.8 \mathrm{~mA} / \mathrm{cm}^{2}$, and an open-circuit voltage of $0.81 \mathrm{~V}$, yielding a power conversion efficiency of $2.8 \%$ under $100 \mathrm{~mW} / \mathrm{cm}^{2}$ air mass $1.5 \mathrm{G}$ illumination.

\section{Experimental section}

\subsection{Large-area flexible solar cells fabrication with an embedded metal grid}

Metal grids embedded within a SU8 thin film were fabricated by first coating a glass substrate with a thin positive photoresist (Microposit SC1813). A $200 \mathrm{~nm}$ thick copper was deposited as a seed layer. The positive photoresist film was used here to promote an easy peel-off at the end of process. On top of this seed layer, a negative photoresist (NR9 1500PY) was coated to create a mold structure (Fig. 1 (a)). A 100 nm-thick gold layer was deposited on top of the mold structure followed by a lift-off process which created honey-comb-shaped metal grids with a width of $40 \mu \mathrm{m}$. An SU8 photoresist was spin-coated and patterned to create trenches (Fig. 1(c)). Copper was electroplated through the trenches (Fig. 1 (d)). Electroplated copper had a width of $20 \mu \mathrm{m}$ and a thickness of $15 \mu \mathrm{m}$. A second layer of SU8 was applied on top of the entire surface, encapsulating the metal grids (Fig. 1 (d)). The fabricated SU8 film with embedded metal grids was then peeled off from the glass substrate (Fig. 1 (e)). Finally, the positive photoresist (SC1813) and $\mathrm{Cu}$ seed layer were removed by using a photoresist remover (Microposit 1165 remover) and $\mathrm{Cu}$ etchant, respectively (Fig. 1 (f)). During the $\mathrm{Cu}$ seed layer etching, electroplated copper grids are protected by gold grids from the $\mathrm{Cu}$ etchant. Au grid could be replaced with other materials such as chrome or nickel as long as the copper seed layer can be etched selectively. Hence, 
the metal grids consisted of an Au layer on top of an electroplated copper layer, noting that the gold grid is wider than the copper by $20 \mu \mathrm{m}$, as shown in Fig. 2.

The flexible substrate with the embedded metal grid was mounted on a glass substrate and secured with a Kapton ${ }^{\mathrm{TM}}$ tape on all four corners during the OPV fabrication. High conductivity PEDOT:PSS (Clevios PH1000) having 5 wt\% DMSO was spincoated at $1000 \mathrm{rpm}$ for $15 \mathrm{~s}$ and annealed on a hotplate at $110^{\circ} \mathrm{C}$ for 15 minutes. Polyethylenimine ethoxylated (PEIE) was spin-coated, from a $4 \mathrm{wt} \%$ solution mixed with 2-methoxyethanol, at $5000 \mathrm{rpm}$ for $60 \mathrm{~s}$ and annealed on a hotplate at $110{ }^{\circ} \mathrm{C}$ for 15 minutes. The active layer of poly(3-hexylthiophene) (P3HT): Indene-C60 BisAdduct (ICBA) (1:1, weight ratio) was spin-coated at $700 \mathrm{rpm}$ for $60 \mathrm{~s}$ in the $\mathrm{N}_{2}$-filled glove box from a chlorobenzene solution $(40 \mathrm{mg} / \mathrm{ml})$ and annealed on a hot plate at $150{ }^{\circ} \mathrm{C}$ for 10 minutes. The device was transferred to a thermal evaporator and $15 \mathrm{~nm}$ of $\mathrm{MoO}_{3}$ and $150 \mathrm{~nm}$ of $\mathrm{Ag}$ top-electrodes were deposited through a shadow mask under high vacuum. The completed device had an active area of $9.3 \pm 0.2 \mathrm{~cm}^{2}$ and an inverted OPV structure of $\quad$ SU8/embedded-metalgrid/PEDOT:PSS(PH1000)/PEIE/P3HT:ICBA/MoO $3 /$ Ag (Fig. 3).

\subsection{Device characterization}

Current density-voltage $(\mathrm{J}-\mathrm{V})$ characteristics were measured inside a $\mathrm{N}_{2}$-filled glove box using a source meter (2400, Keithley Instruments) in a four-wire connection scheme. A solar simulator (91160, Newport Oriel) equipped with a 300W xenon lamp (6258, Newport) with an air mass (AM) 1.5 filter and providing an irradiance of $100 \mathrm{~mW} / \mathrm{cm}^{2}$ was used as the light source. A Si photodiode (Hamamatsu S1133) calibrated by NREL was used to calibrate the intensity of the solar simulator. 


\section{Results and discussion}

The structure of organic solar cells on grid-embedded substrates is shown in Fig. 3 and the complete device is shown in Fig. 4 exhibiting a smooth aluminum surface and the flexibility of a substrate. The surface of PH1000 was modified with PEIE in order to reduce its work function; enable it to act as an electron collection electrode [36]. The metal grids reduce the light-collection area of the device by $5.5 \%$ due to shadowing effects (Fig. 2).

Fig. 5 shows the current density - voltage $(J-V)$ characteristics of a solar cell fabricated with an embedded metal grid within an SU8 substrate in the dark and under illumination. In the dark, the device shows low current under reverse bias and a shunt resistance value of $20.1 \mathrm{k} \Omega-\mathrm{cm}^{2}$. This indicates that an active layer with a relatively low density of defects was successfully coated over a large area. Under $100 \mathrm{~mW} / \mathrm{cm}^{2}$ of AM 1.5G illumination, the device displays $V_{\mathrm{OC}}=808 \pm 5 \mathrm{mV}, J_{\mathrm{SC}}=5.5 \pm 0.5$ $\mathrm{mA} / \mathrm{cm}^{2}$, and $F F=0.53 \pm 0.06$, yielding a PCE $=2.4 \pm 0.4 \%$ (Table 1). The device has an active area of $9.3 \pm 0.2 \mathrm{~cm}^{2}$. Averages and standard deviations were based on measurements of 4 devices. Our previous report also included device performances based on a smaller active area of $0.1 \mathrm{~cm}^{2}$ fabricated on a glass substrate, but with the same device structure [36], i.e., Glass/PH1000/PEIE/P3HT:ICBA/MoO $3 / \mathrm{Ag}$. It exhibited $V_{\mathrm{OC}}=0.79 \pm 0.03 \mathrm{~V}, J_{\mathrm{SC}}=7.6 \pm 0.2 \mathrm{~mA} / \mathrm{cm}^{2}$, and $F F=0.57 \pm 0.02$ yielding a PCE $=3.5 \pm 0.3 \%$, averaged over 10 devices [36]. Compared with this small area device, the new device with an embedded metal grids shows comparable performance for the $V_{\mathrm{OC}}(0.81 v s .0 .79 \mathrm{~V})$ and $F F(0.53$ vs. 0.57). Comparable $F F$ values indicate that the new device does not suffer from significant resistive power losses thanks to the embedded thick metal grids. In fact, its series resistance value (6.5 $\Omega-\mathrm{cm}^{2}$ ) is within the range of the large-area OPV devices that we built on glass 
substrates by integrating metal grids with either ITO or PEDOT:PSS [22, 23]. However, the value of $J_{\mathrm{SC}}$ of the large-area device is around $72 \%$ that of a small-area device fabricated on a glass substrate $\left(5.5 v s .7 .6 \mathrm{~mA} / \mathrm{cm}^{2}\right)$ [36]. To account for these differences, the transmittance of Glass/SU8 $(20 \mu \mathrm{m})$ was measured and found to be in the range between 87 and $90 \%$ within the visible spectral range $(390-700 \mathrm{~nm})$ as shown in Fig. 6. The transmittance of the embedded metal grid on the flexible SU8 substrate was in the range between 68 and $76 \%$ and slightly reduced to the range between 67 and $70 \%$ with the addition of the PH1000 layer. In our previous report [22], the transmittance of glass/PH1000(134nm) was found to be in the range between 91 and $82 \%$ within the visible wavelength range, significantly higher than that of the flexible substrate with an embedded metal grid. Hence, the metal grid seems to account for around $15 \%$ (out of $28 \%$ reduction) of the $J_{\mathrm{SC}}$ reduction observed between large area and small area solar cell devices. This value is significantly larger than the $5.5 \%$ shadowing area loss and represents a maximum bound to the transmittance loss induced by the embedded metal grid. This is because the transmittance could be reduced not only by shadowing but because light diffracted or scattered by the embedded metal grid could be falling off the field-of-view of the detector. The remaining losses of $J_{\mathrm{SC}}$, estimated to be between $13 \%$ to $22.5 \%$, could be attributed to differences in the thermal properties of the substrates (i.e. glass vs. SU8) leading to active layer films with slightly different morphology during the thermal annealing process compared to devices on glass. Further optimization of the thermal annealing process is expected to improve the $J_{\mathrm{SC}}$ values of these large area solar cells.

As the amount of photo-generated current increases either by improved power conversion efficiency or concentrated sunlight, the thick metal grid method provides 
unique benefit when handling large current with minimized power loss from the grid itself.

\section{Summary}

In this work we have demonstrated an ITO-free large-area OPV on a flexible substrate. A high conductivity PEDOT:PSS (PH1000) was used as a transparent electrode and combined with electroplated thick metal grid which was embedded within a flexible SU8 substrate. Because the thick metal grid was embedded within a flexible substrate, we were able to spin coat thin layers of PEDOT:PSS and organic semiconductors uniformly on top of the large-area substrate. By making metal grids thicker, a highly conductive current path was implemented while minimizing shadow loss. The SU8 photo-patternable polymer used as flexible substrate exhibited good optical transmittance in the visible wavelength range. The metal grid reduces the collection area of the solar cell by $5.5 \%$. A solar cell with structure of SU8:embeddedmetal-grid/PEDOT:PSS(PH1000)/PEIE/P3HT:ICBA/MoO $3 / \mathrm{Ag}$ with an active area of of $9.3 \pm 0.2 \mathrm{~cm}^{2}$ exhibited a fill factor of $0.53 \pm 0.06$ and an open-circuit voltage of $808 \pm 5 \mathrm{mV}$ which are comparable with values measured in small area devices. The power conversion efficiency of the large-area solar cell is $2.4 \pm 0.4 \%$ under 100 $\mathrm{mW} / \mathrm{cm}^{2}$ air mass $1.5 \mathrm{G}$ illumination.

We note that the device performance achieved in this work is not comparable to that of the best small-area OPVs based on P3HT:ICBA largely due to a flexible substrate (SU8) with less optical transmittance and process difficulties associated with the processing of the organic semiconductor films over larger areas. However, by using this photo-patternable polymer as a flexible substrate, we were able to demonstrate new device architecture where thick metal grids were embedded, hence, 
allowing organic semiconductors to be spin-coated more uniformly compared to the devices where metal grids were fabricated on top of a substrate. Power conversion efficiency could be further improved by optimizing thermal annealing and the coating methods used to fabricate larger area films. Future studies will focus on the optimization of these process conditions.

\section{Acknowledgements}

This research was funded in part through the center for interface science: solar electric materials, an energy frontier research center funded by the US Department of Energy, Office of Science, and Office of Basic Energy Sciences under award number DESC0001084. 


\section{References}

[1] B. Kippelen, J.-L. Bredas, Organic photovoltaics, Energy \& Environmental Science, 2 (2009) 251-261.

[2] W. Cao, J. Xue, Recent progress in organic photovoltaics: device architecture and optical design, Energy \& Environmental Science, 7 (2014) 2123-2144.

[3] T.R. Andersen, H.F. Dam, M. Hosel, M. Helgesen, J.E. Carle, T.T. Larsen-Olsen, S.A. Gevorgyan, J.W. Andreasen, J. Adams, N. Li, F. Machui, G.D. Spyropoulos, T. Ameri, N. Lemaitre, M. Legros, A. Scheel, D. Gaiser, K. Kreul, S. Berny, O.R. Lozman, S. Nordman, M. Valimaki, M. Vilkman, R.R. Sondergaard, M. Jorgensen, C.J. Brabec, F.C. Krebs, Scalable, ambient atmosphere roll-to-roll manufacture of encapsulated large area, flexible organic tandem solar cell modules, Energy \& Environmental Science, (2014).

[4] J. You, C.-C. Chen, Z. Hong, K. Yoshimura, K. Ohya, R. Xu, S. Ye, J. Gao, G. Li, Y. Yang, 10.2\% Power Conversion Efficiency Polymer Tandem Solar Cells Consisting of Two Identical Sub-Cells, Advanced Materials, 25 (2013) 39733978.

[5] J. You, L. Dou, K. Yoshimura, T. Kato, K. Ohya, T. Moriarty, K. Emery, C.-C. Chen, J. Gao, G. Li, Y. Yang, A polymer tandem solar cell with $10.6 \%$ power conversion efficiency, Nat Commun, 4 (2013) 1446.

[6] S.-I. Na, S.-S. Kim, J. Jo, D.-Y. Kim, Efficient and Flexible ITO-Free Organic Solar Cells Using Highly Conductive Polymer Anodes, Advanced Materials, 20 (2008) 4061-4067.

[7] R. Paetzold, K. Heuser, D. Henseler, S. Roeger, G. Wittmann, A. Winnacker, Performance of flexible polymeric light-emitting diodes under bending conditions, Applied Physics Letters, 82 (2003) 3342-3344.

[8] Y. Zhou, F. Zhang, K. Tvingstedt, S. Barrau, F. Li, W. Tian, O. Inganas, Investigation on polymer anode design for flexible polymer solar cells, Applied Physics Letters, 92 (2008) 233308.

[9] G.P. Kushto, W. Kim, Z.H. Kafafi, Flexible organic photovoltaics using conducting polymer electrodes, Applied Physics Letters, 86 (2005) 093502.

[10] C. Zhang, D. Zhao, D. Gu, H. Kim, T. Ling, Y.-K.R. Wu, L.J. Guo, An Ultrathin, Smooth, and Low-Loss Al-Doped Ag Film and Its Application as a Transparent Electrode in Organic Photovoltaics, Advanced Materials, 26 (2014) 5696-5701.

[11] J. Zou, C.-Z. Li, C.-Y. Chang, H.-L. Yip, A.K.Y. Jen, Interfacial Engineering of Ultrathin Metal Film Transparent Electrode for Flexible Organic Photovoltaic Cells, Advanced Materials, 26 (2014) 3618-3623.

[12] S.K. Hau, H.-L. Yip, K. Leong, A.K.Y. Jen, Spraycoating of silver nanoparticle electrodes for inverted polymer solar cells, Organic Electronics, 10 (2009) 719723.

[13] J. Meiss, M.K. Riede, K. Leo, Towards efficient tin-doped indium oxide (ITO)free inverted organic solar cells using metal cathodes, Applied Physics Letters, 94 (2009) 013303.

[14] A. Haldar, S.D. Yambem, K.-S. Liao, N.J. Alley, E.P. Dillon, A.R. Barron, S.A. Curran, Organic photovoltaics using thin gold film as an alternative anode to indium tin oxide, Thin Solid Films, 519 (2011) 6169-6173.

[15] A. Kim, Y. Won, K. Woo, S. Jeong, J. Moon, All-Solution-Processed IndiumFree Transparent Composite Electrodes based on Ag Nanowire and Metal Oxide for Thin-Film Solar Cells, Advanced Functional Materials, 24 (2014) 2462-2471. 
[16] A.B.V.K. Kumar, J. Jiang, C.W. Bae, D.M. Seo, L. Piao, S.-H. Kim, Silver nanowire/polyaniline composite transparent electrode with improved surface properties, Materials Research Bulletin, 57 (2014) 52-57.

[17] Y. Galagan, J.-E. J.M. Rubingh, R. Andriessen, C.-C. Fan, P. W.M. Blom, S. C. Veenstra, J. M. Kroon, ITO-free flexible organic solar cells with printed current collecting grids, Solar Energy Materials and Solar Cells, 95 (2011) 1339-1343.

[18] M.-G. Kang, M.-S. Kim, J. Kim, L.J. Guo, Organic Solar Cells Using Nanoimprinted Transparent Metal Electrodes, Advanced Materials, 20 (2008) 4308-4313.

[19] J. Zou, H.-L. Yip, S.K. Hau, A.K.-Y. Jen, Metal grid/conducting polymer hybrid transparent electrode for inverted polymer solar cells, Applied Physics Letters, 96 (2010) 203301.

[20] M.-G. Kang, H. Joon Park, S. Hyun Ahn, L. Jay Guo, Transparent Cu nanowire mesh electrode on flexible substrates fabricated by transfer printing and its application in organic solar cells, Solar Energy Materials and Solar Cells, 94 (2010) 1179-1184.

[21] K. Tvingstedt, O. Inganäs, Electrode Grids for ITO Free Organic Photovoltaic Devices, Advanced Materials, 19 (2007) 2893-2897.

[22] S. Choi, W.J. Potscavage, B. Kippelen, ITO-free large-area organic solar cells, Opt. Express, 18 (2010) A458-A466.

[23] S. Choi, W.J. Potscavage, Jr., B. Kippelen, Area-scaling of organic solar cells, Journal of Applied Physics, 106 (2009) 054507.

[24] H. Jin, A. Pivrikas, K.H. Lee, M. Aljada, M. Hambsch, P.L. Burn, P. Meredith, Factors Influencing the Efficiency of Current Collection in Large Area, Monolithic Organic Solar Cells, Advanced Energy Materials, 2 (2012) 13381342.

[25] A.J. Das, K.S. Narayan, Retention of Power Conversion Efficiency - From Small Area to Large Area Polymer Solar Cells, Advanced Materials, 25 (2013) 21932199.

[26] F.C. Krebs, All solution roll-to-roll processed polymer solar cells free from indium-tin-oxide and vacuum coating steps, Organic Electronics, 10 (2009) 761768.

[27] B. Zimmermann, H.F. Schleiermacher, M. Niggemann, U. Würfel, ITO-free flexible inverted organic solar cell modules with high fill factor prepared by slot die coating, Solar Energy Materials and Solar Cells, 95 (2011) 1587-1589.

[28] R.R. Søndergaard, M. Hösel, F.C. Krebs, Roll-to-Roll fabrication of large area functional organic materials, Journal of Polymer Science Part B: Polymer Physics, 51 (2013) 16-34.

[29] D. Angmo, S.A. Gevorgyan, T.T. Larsen-Olsen, R.R. Søndergaard, M. Hösel, M. Jørgensen, R. Gupta, G.U. Kulkarni, F.C. Krebs, Scalability and stability of very thin, roll-to-roll processed, large area, indium-tin-oxide free polymer solar cell modules, Organic Electronics, 14 (2013) 984-994.

[30] F.C. Krebs, T. Tromholt, M. Jorgensen, Upscaling of polymer solar cell fabrication using full roll-to-roll processing, Nanoscale, 2 (2010) 873-886.

[31] F.C. Krebs, S.A. Gevorgyan, J. Alstrup, A roll-to-roll process to flexible polymer solar cells: model studies, manufacture and operational stability studies, Journal of Materials Chemistry, 19 (2009) 5442-5451.

[32] S. Choi, S.-J. Kim, C. Fuentes-Hernandez, B. Kippelen, ITO-free large-area organic light-emitting diodes with an integrated metal grid, Opt. Express, 19 (2011) A793-A803. 
[33] S. Choi, W.J. Potscavage, Jr., B. Kippelen, Area-scaling of Organic Solar Cells and Integrated Modules, in: J. Xue (Ed.) Organic Materials and Devices for Sustainable Energy Systems, Mat. Res. Soc. Symp. Proc., Boston, MA, USA, 2009, pp. S06.

[34] J.-S. Yu, G.H. Jung, J. Jo, J.S. Kim, J.W. Kim, S.-W. Kwak, J.-L. Lee, I. Kim, D. Kim, Transparent conductive film with printable embedded patterns for organic solar cells, Solar Energy Materials and Solar Cells, 109 (2013) 142-147.

[35] H.J.v.d. Wiel, Y. Galagan, T.J.v. Lammeren, J.F.J.d. Riet, J. Gilot, M.G.M. Nagelkerke, R.H.C.A.T. Lelieveld, S. Shanmugam, A. Pagudala, D. Hui, W.A. Groen, Roll-to-roll embedded conductive structures integrated into organic photovoltaic devices, Nanotechnology, 24 (2013) 484014.

[36] Y. Zhou, C. Fuentes-Hernandez, J. Shim, J. Meyer, A.J. Giordano, H. Li, P. Winget, T. Papadopoulos, H. Cheun, J. Kim, M. Fenoll, A. Dindar, W. Haske, E. Najafabadi, T.M. Khan, H. Sojoudi, S. Barlow, S. Graham, J.-L. Brédas, S.R. Marder, A. Kahn, B. Kippelen, A Universal Method to Produce Low-Work Function Electrodes for Organic Electronics, Science, 336 (2012) 327-332. 


\section{Figures}

(a)
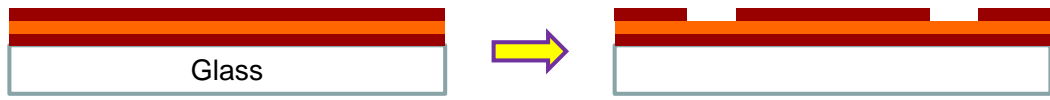

(b)
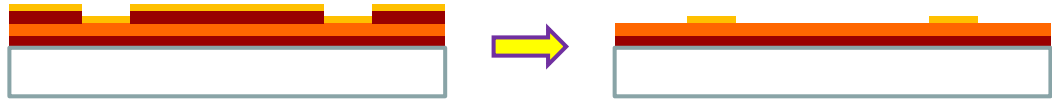

(c)
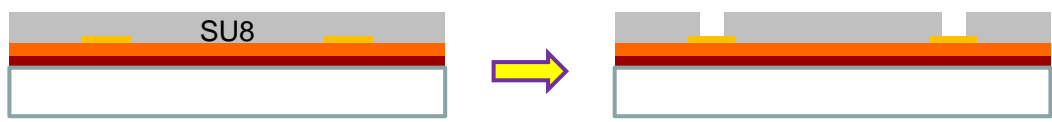

(d)
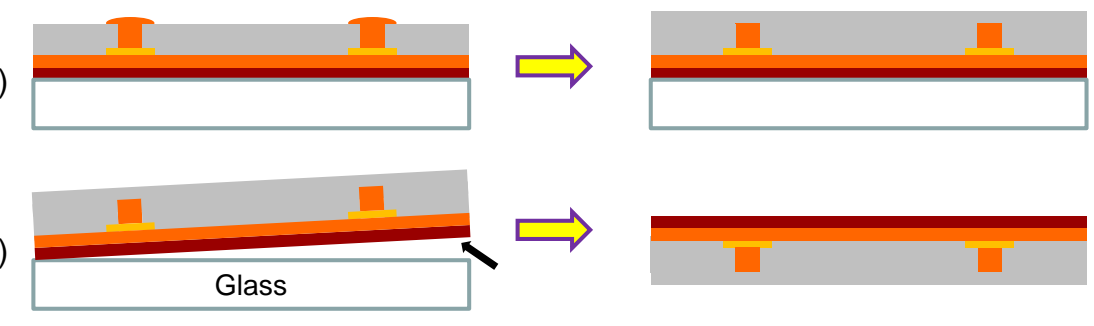

(e)

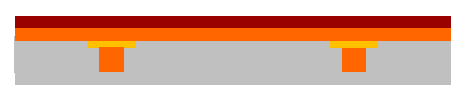

(f)
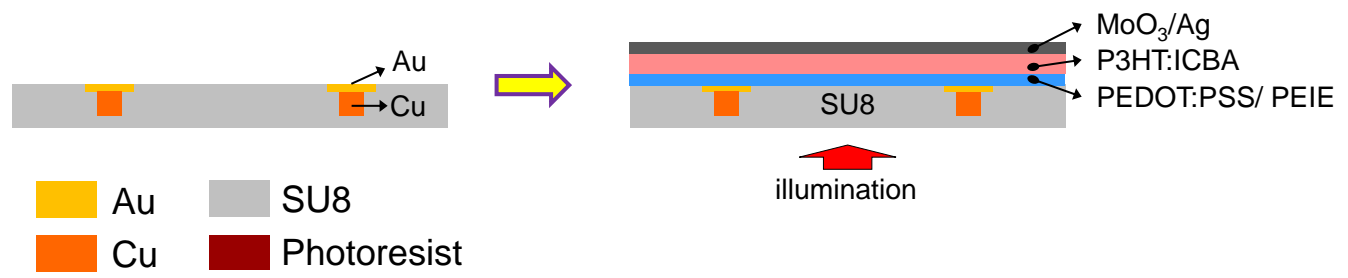

Figure 1. Fabrication sequences for ITO-free large-area organic solar cell with embedded grids: (a) seed layer deposition and mold structure creation for Au grids, (b) $\mathrm{Au}$ deposition and lift-off, (c) SU8 spin coating and patterning; (d) copper grid electroplating, (e) peel-off the flexible substrate from the glass, (f) seed layer removal and OPV fabrication. 


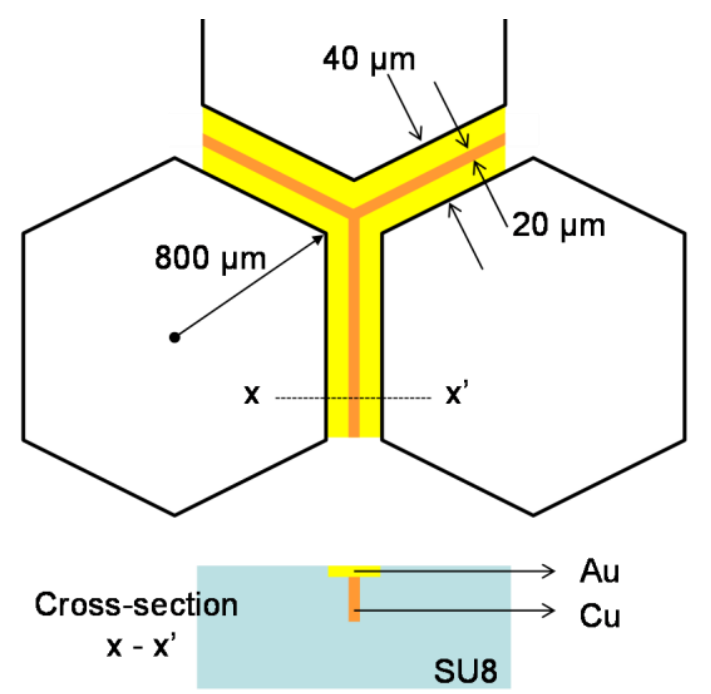

Figure 2. Metal grids design with two layers of metals: Au on top of electroplated copper. Gold grid is wider than copper by $20 \mu \mathrm{m}$ and protects electroplated copper from the $\mathrm{Cu}$ etchant during the seed layer etching. The device has a $5.5 \%$ of shadowing area over which incoming light is blocked due to the metal grids. 


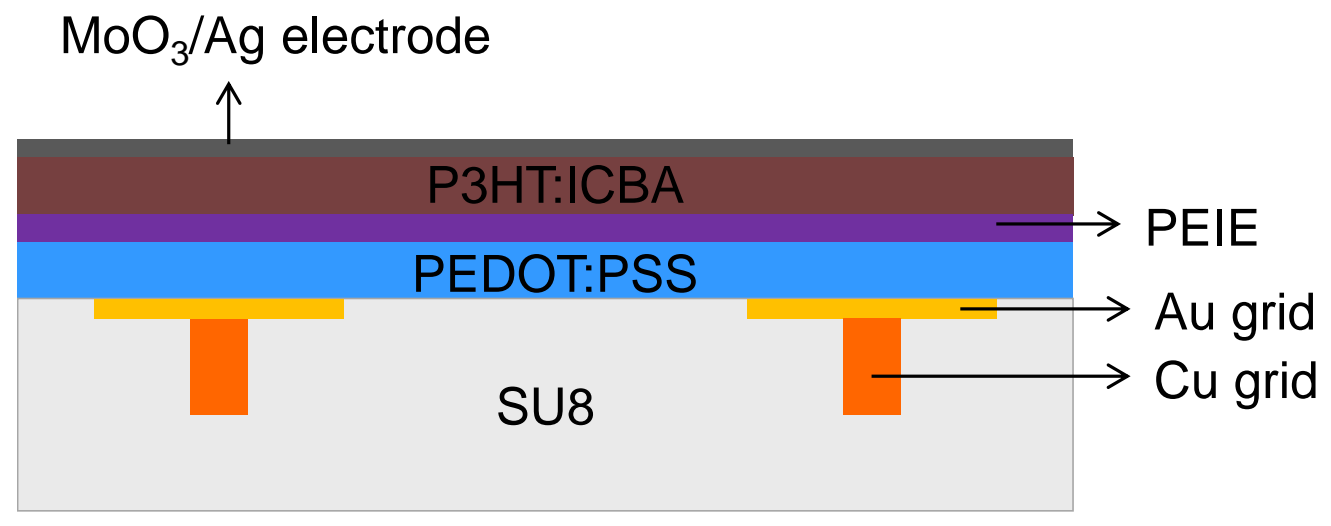

Figure 3. Cross-sectional view of the ITO-free flexible OPV with an embedded metal grid (active area: $9.3 \mathrm{~cm}^{2}$ ) 

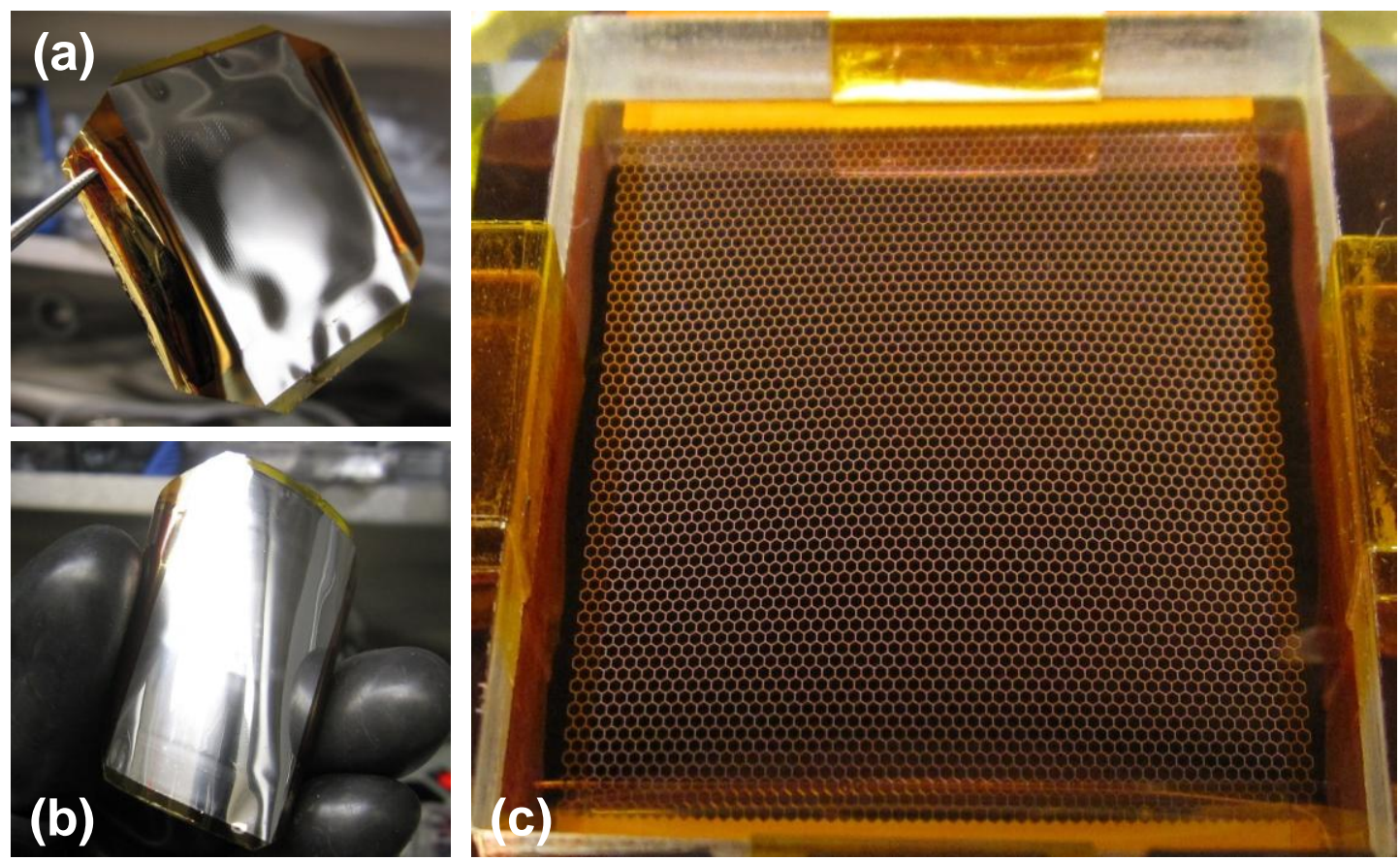

Figure 4. Device pictures of ITO-free large-area flexible organic solar cells with an embedded metal grid: Front (a, b) and back (c). 


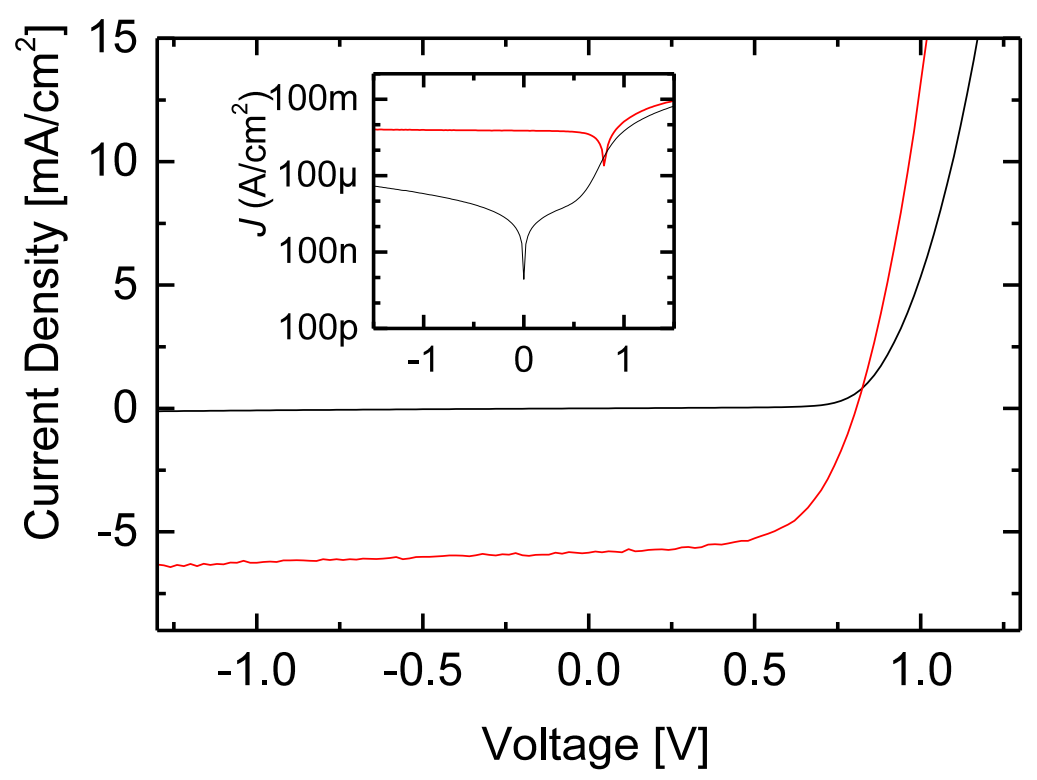

Figure 5. $J-V$ characteristics in the dark and under illumination $\left(100 \mathrm{~mW} / \mathrm{cm}^{2}\right)$ of AM1.5G illumination for solar cells with embedded metal on a flexible SU8 substrate. The insets are the $J-V$ characteristics in the dark and under illumination on a semilogarithmic scale. 


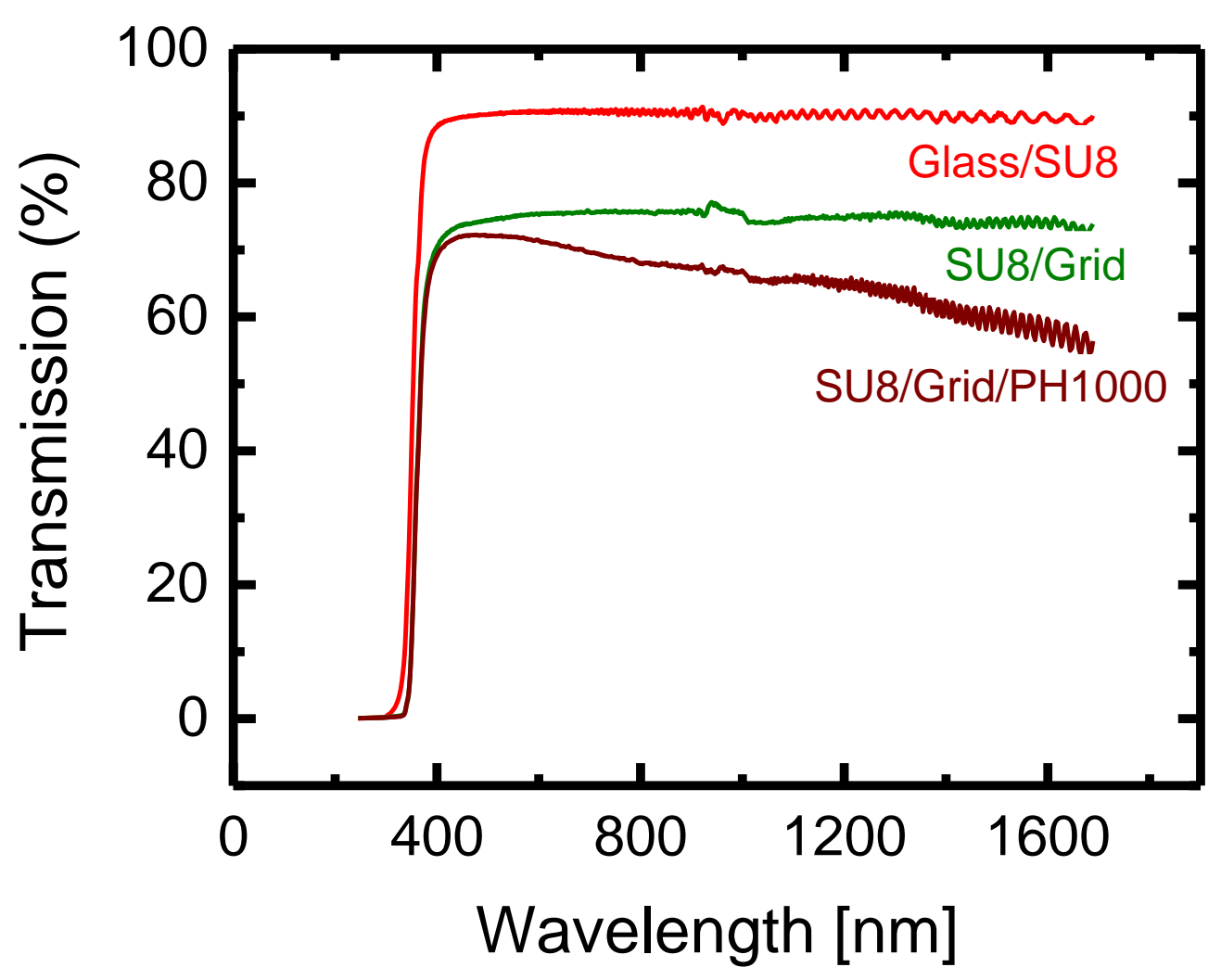

Figure 6. Transmission spectra of SU8 on glass, SU8 with embedded metal grids, and embedded metal grids with PEDOT:PSS (PH1000).

Table 1. Summary of the photovoltaic parameters measured in solar cells with embedded metal grids. Measured $R_{\mathrm{S}} A$ and $R_{\mathrm{P}} A$ are extracted from the inverse slope of the forward and reverse characteristics under illumination, respectively in Fig. 5. Averages and standard deviations were based on measurements of 4 devices.

\begin{tabular}{|c|c|c|c|c|c|c|}
\hline $\begin{array}{c}\text { Area } \\
{\left[\mathrm{cm}^{2}\right]}\end{array}$ & $\begin{array}{c}J_{\mathrm{SC}} \\
{\left[\mathrm{mA} / \mathrm{cm}^{2}\right]}\end{array}$ & $\begin{array}{c}V_{\mathrm{OC}} \\
{[\mathrm{mV}]}\end{array}$ & $\mathrm{FF}$ & $\begin{array}{c}R_{S} A \\
{\left[\Omega-\mathrm{cm}^{2}\right]}\end{array}$ & $\begin{array}{c}R_{P} A \\
{\left[\mathrm{k} \Omega-\mathrm{cm}^{2}\right]}\end{array}$ & $\begin{array}{c}\eta \\
{[\%]}\end{array}$ \\
\hline $9.3 \pm 0.2$ & $5.5 \pm 0.5$ & $\begin{array}{c}808 \pm \\
5\end{array}$ & $\begin{array}{c}0.53 \pm \\
0.06\end{array}$ & $6.5 \pm 0.9$ & $20 \pm 16$ & $2.4 \pm 0.4$ \\
\hline
\end{tabular}


(a)
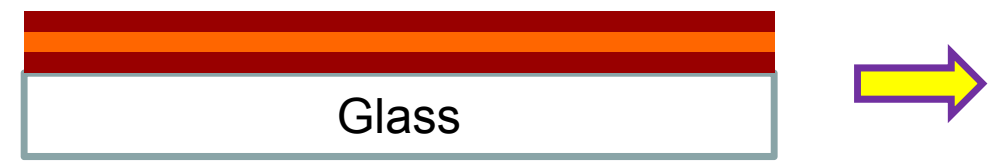

(b)
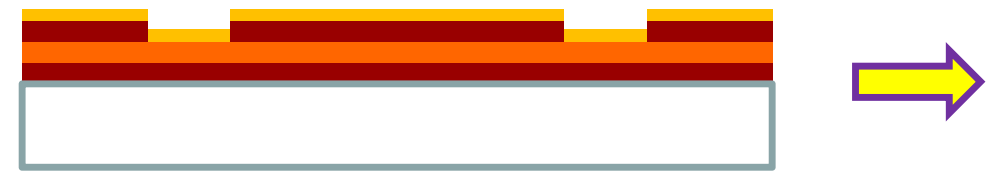

(c)
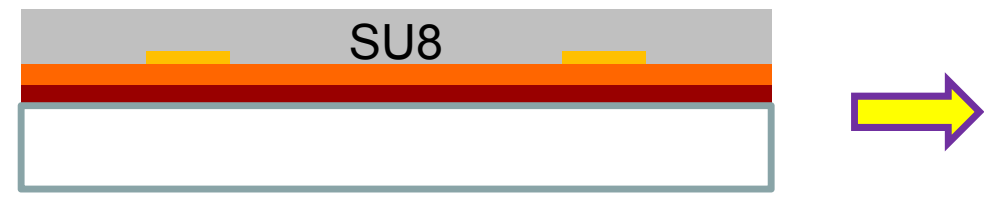

(d)
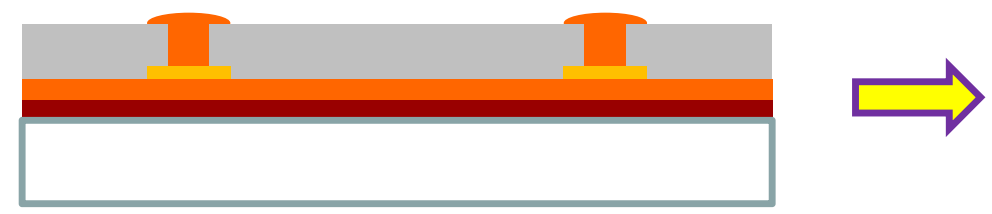

(e)

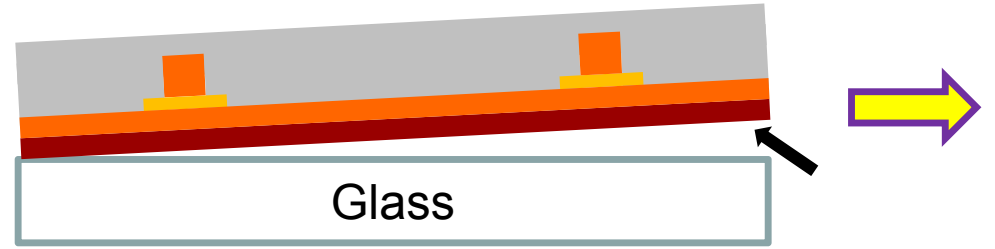

(f)

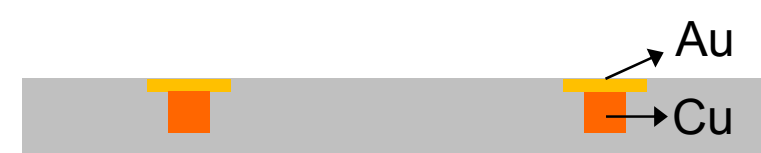

$\mathrm{Au}$

SU8

$\mathrm{Cu} \quad$ Photoresist

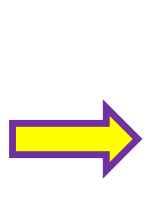

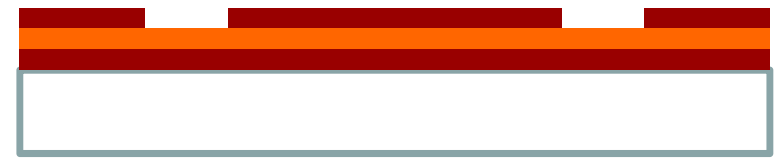
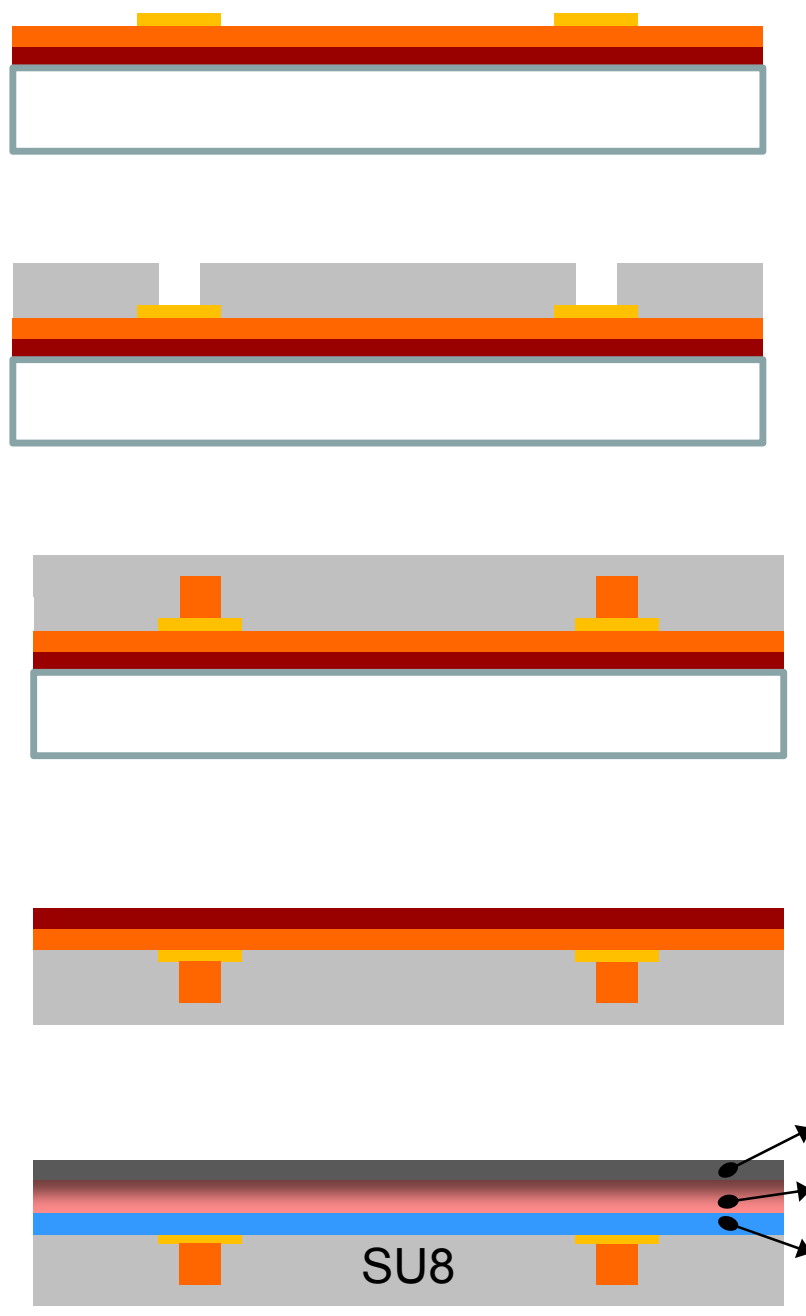

\section{$\mathrm{MoO}_{3} / \mathrm{Ag}$}

P3HT:ICBA

PEDOT:PSS/ PEIE illumination 


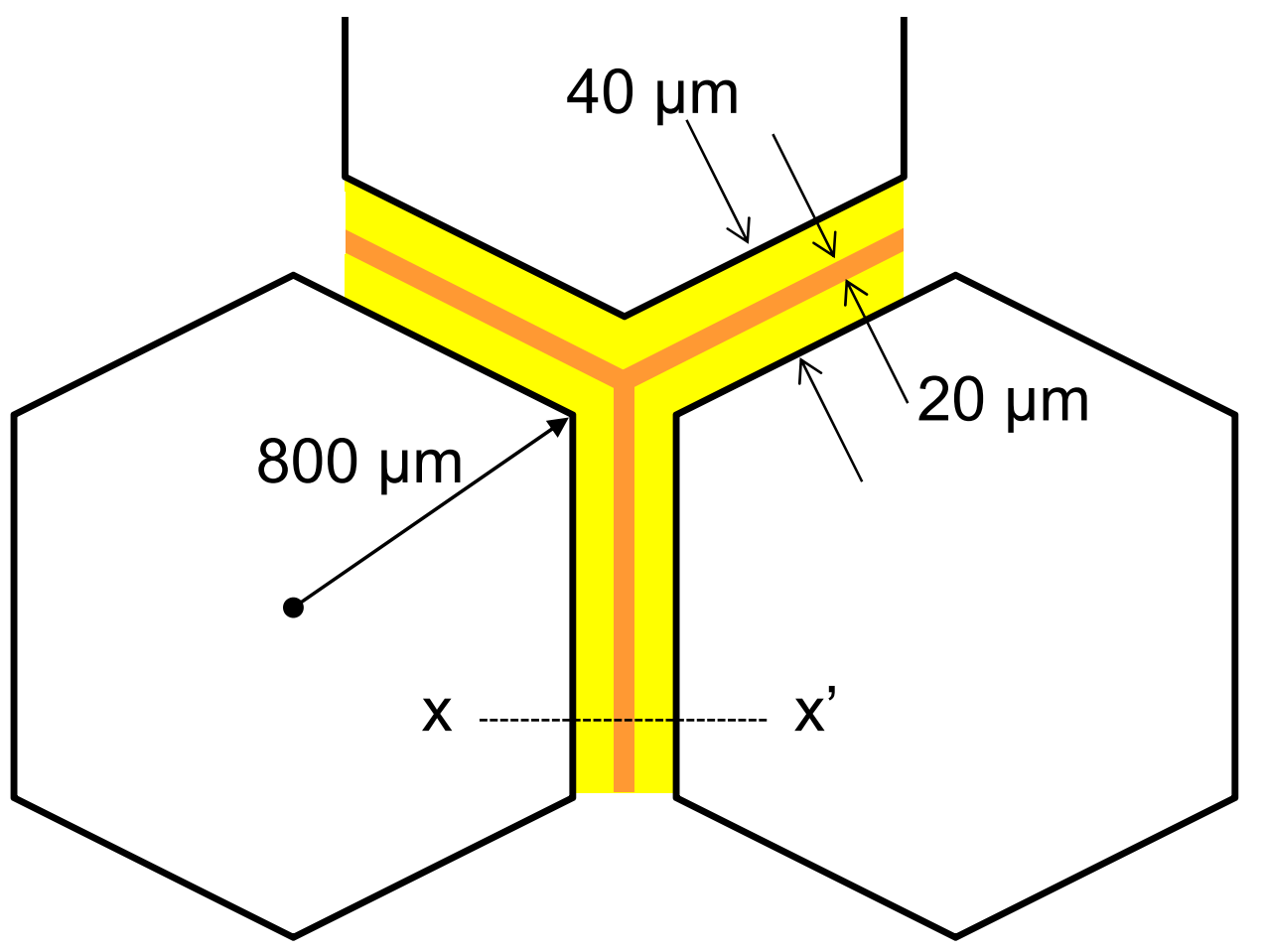

\section{Cross-section

$$
x-x^{\prime}
$$

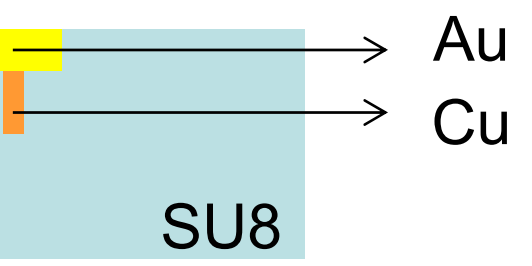


$\mathrm{MoO}_{3} / \mathrm{Ag}$ electrode

\section{P3HT:ICBA \\ PEDOT:PSS}

PEIE

SU8

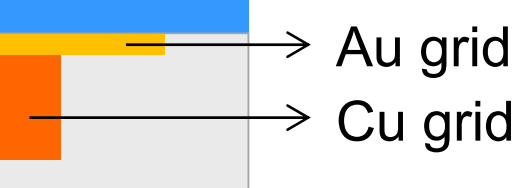




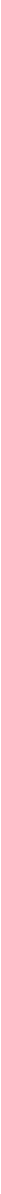


Figure 5

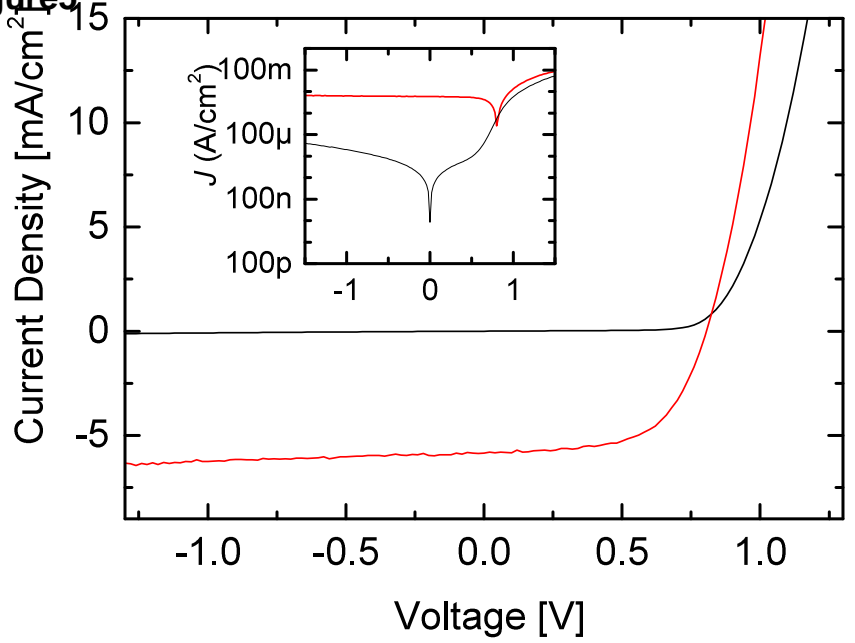




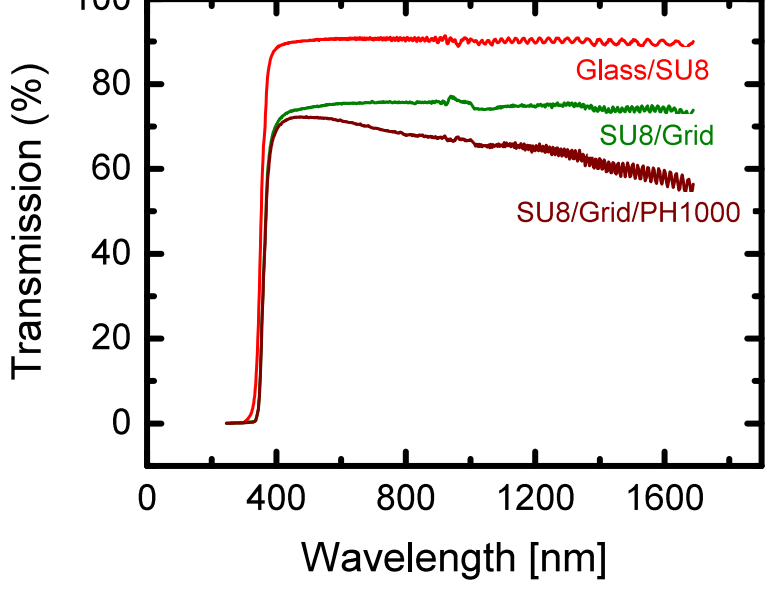

